\title{
Investigations of Protein Structure and Function Using the Scientific Literature: An Assignment for an Undergraduate Cell Physiology Course
}

\author{
Amy B. Mulnix
}

Department of Biology, Drawer 83, Earlham College, 801 National Road West, Richmond, Indiana 47374

Submitted June 9, 2003; Revised August 14, 2003; Accepted September 11, 2003

Monitoring Editor: James Gentile

\begin{abstract}
Undergraduate biology curricula are being modified to model and teach the activities of scientists better. The assignment described here, one that investigates protein structure and function, was designed for use in a sophomore-level cell physiology course at Earlham College. Students work in small groups to read and present in poster format on the content of a single research article reporting on the structure and/or function of a protein. Goals of the assignment include highlighting the interdependence of protein structure and function; asking students to review, integrate, and apply previously acquired knowledge; and helping students see protein structure/function in a context larger than cell physiology. The assignment also is designed to build skills in reading scientific literature, oral and written communication, and collaboration among peers. Assessment of student perceptions of the assignment in two separate offerings indicates that the project successfully achieves these goals. Data specifically show that students relied heavily on their peers to understand their article. The assignment was also shown to require students to read articles more carefully than previously. In addition, the data suggest that the assignment could be modified and used successfully in other courses and at other institutions.
\end{abstract}

Keywords: undergraduate, protein, literature, assignment, poster.

\section{INTRODUCTION}

A variety of calls has been made at the national level (NSF Division of Science Education, 1996; Rothman and Narum, 1999; National Research Council, 2003) for an undergraduate biology curriculum that better models and teaches the activities of science, including greater emphasis on quantitative analysis, more attention to the interdisciplinary nature of contemporary biology, and inclusion of investigative projects in classroom and laboratory activities. Biology 2010: Transforming Undergraduate Education for Future Research Biologists (National Research Council, 2003) names inquiry-based learning as one way to improve undergraduate teaching:

\begin{abstract}
[T] he main idea of inquiry is for students to learn in the same way that scientists learn through research. Scientists ask questions, make observations, take measurements, analyze data, and repeat this process in an attempt to integrate new information. Students should be taught the way scientists think about the world, and how they analyze a scientific problem in particular. (p. 16)
\end{abstract}

A specific skill that is often overlooked in these national discussions of teaching the process of science is using the

DOI: $10.1187 /$ cbe.03-06-0025

Corresponding author. E-mail address: amymul@earlham.edu. scientific literature. As an undeniably important source of information for scientists, the research literature should be a critical training ground for young science professionals. A few authors (Janick-Buckner, 1997; Herman, 1999; Edwards et al., 2001; Levine, 2001) have published descriptions of assignments that incorporate primary literature and many faculty teach specialized literature-based seminars in their upper level courses. However, using the scientific literature is often reserved for advanced students or is peripheral to daily classroom activities.

Not only does teaching students to work with the scientific literature model the activities of scientists, but having students read, interpret, analyze, and report on the research literature provides opportunities to develop critical and analytical thinking and written and/or oral communication. Edwards et al. (2001) describe a literature-based assignment, part of which includes students writing letters to the editors of journals regarding a research paper; 18 of the 85 letters (21\%) were published in peer-reviewed journals. This suggests that students were gaining experience in critical analysis as determined by established scientists in a field. Furthermore, assignments based on the primary literature can prepare students to succeed in contemporary biology, incorporating quantitative analysis, emphasizing the interdisciplinary nature of biology, and introducing investigative, open-ended questions. Properly designed, literature analysis assignments also can help 
students gain confidence, integrate material, and see applications of a particular topic to broader areas of biology. Herman (1999) reports that students taught to work in the primary literature in her molecular genetics course retain and integrate material better than when she used a traditional lecture format. Students also are able to experience the vitality and ambiguity of a field, learning that as many questions are raised as are answered in the process of research. Textbooks rarely provide this kind of glimpse into science as a process.

Learning to analyze a research article is a challenge for undergraduates. Providing students with assignments that ask for progressively more sophisticated interpretation and analysis can develop these skills over their undergraduate careers. The biology curriculum at Earlham College has taken such an approach for over three decades (Stephenson, 1993).

Thirty-five to forty majors graduate each year from Earlham's biology department, which consists of six full-time faculty equivalents. Our introductory-level courses enroll between 60 and 120 students, including those intending to major in biology, as well as those taking the courses for a general education requirement. The majority of our majors pursue postbaccalaureate education within 2 years of graduation; Earlham ranks eighth nationally (Higher Education Data Sharing Consortium, 2002) in the number of students that go on to pursue doctoral degrees in the life sciences.

To begin building proficiency in literature analysis, the department has structured assignments across the first-year courses to introduce the research literature. In an effort to further develop these skills, the assignment described here, one used in a sophomore level cell physiology course, was designed to bridge the experiences in our introductory courses and in our upper-level courses, which are often run in a seminar format. The structure of the assignment is also a response to the national calls to improve undergraduate biology curricula, particularly in the cellular/molecular areas. Evaluation of the assignment in meeting both content- and skill-based goals has been conducted by measuring student perceptions at the end of the project.

\section{PROFILE OF STUDENTS IN CELL PHYSIOLOGY}

Table 1 gives details about the students enrolled in the cell physiology course. We have used the assignment twice. Of the 77 students in the classes in 2001 and 2002, most were sophomores. The first year the assignment was used, I teamtaught the course with a second colleague; in 2002, a third member of the department taught the course. The course, required of all majors, is taught in 80 -min blocks twice a week.

Nearly $60 \%$ of the students reported that they had read more than 16 articles (with $35 \%$ of the total saying that they had read $>25$ ) (Table 1). Interpretation of this number means that even sophomores in the course have significant prior experience analyzing research articles. Despite the large number reporting that they had read a substantial number of articles, many still indicated that they had only a low to middle level of confidence about their abilities specifically in cellular and molecular biology at the beginning of the assignment (Table 1). In addition to the breakdown presented in Table 1, when asked on a scale of 1 to 5 (with 1 being low and 5 being high) "What level of anxiety did you have about reading the articles?" the averages obtained were 2.98 in 2001 and 2.90 in 2002 (see Table 4).

Table 1. Profile of students enrolled in the cell physiology course

Approximately 40 students

Previous biology and chemistry classes

Student year in school

Student experience reading articles

Confidence reading articles in cell/ molecular areas
Biology and biochemistry majors Most students have had at least

1 year of biology and 1 full year of chemistry, including a semester of organic chemistry.

$59.7 \%$ sophomores

$22.1 \%$ juniors

$16.9 \%$ seniors

$1.3 \%$ other

$35.0 \%$ have read $<25$ articles $25.9 \%$ have read $16-25$ articles $18.1 \%$ have read $8-16$ articles $21.0 \%$ have read $1-8$ articles

$5.3 \%$ very confident $34.7 \%$ pretty confident $44 \%$ somewhat confident $16 \%$ not confident

Two Other Features of the Backgrounds of our Students Are Relevant to this Assignment. Students were familiar with presenting in a poster format from an introductory-level biology course (Mulnix and Penhale, 1997). Students also have extensive experience working in small groups. For example, in our introductory genetics course a group of three or four students investigates a genetic disease using the National Centers for Biotechnology Information (NCBI) database (Mulnix and Penhale, 1997); the majority of the students also had taken ecological biology, a course in which they do a small-group research project.

\section{THE ASSIGNMENT}

\section{General Description}

Our content-based goals for the assignment are: (1) highlighting the importance of chemical principles to protein structure and function; (2) demonstrating the dependence of protein function on structure; (3) making clear the importance of protein structure and function to a variety of levels of biology; (4) highlighting the role of proteins in a context larger than cellular biology; and (5) providing students an opportunity to review, integrate, and apply principles of protein structure and function in a new situation. A number of skill-based goals besides gaining experience with research articles were also addressed by this assignment, including improving written and oral communication and the ability to work as part of a team.

Students worked in pairs or triplets to understand the basics of a single research article (see Table 2 for examples of articles). The publications dealt with an aspect of the structure and/or function of a protein; typically, the paper reported a protein's three-dimensional structure. Students then presented a summary of that paper to their classmates in a "poster session" during a class period.

In order to control content of the articles, faculty selected recent publications from which student pairs or triplets chose one. Articles that reported on proteins with which the students were familiar either from their first-year genetics course or from material presented early in the semester of the cell physiology course were given preference. Attention also was 
Table 2. Examples of articles used in the assignment

Liou YC, Tocilj A, Davies PL, Jia Z. 2000. Mimicry of ice structure by surface hydroxyls and water of a beta-helix antifreeze protein. Nature 406, 322-324

Luecke H, Schobert B, Lanyi JK, Spudich EN, Spudich JL. 2001. Crystal structure of sensory rhodopsin II at 2.4 angstroms: Insights into color tuning and transducer interaction. Science 293, 1499-1503

Otterbein LR, Graceffa P, Dominguez R. 2001. The crystal structure of uncomplexed actin in the ADP state. Science 293, 708-711

Saphire EO, Parren PWHI, Pantophlet R, Zwick MB, Morris GM, Rudd PM, Dwek RA, Stanfield RL, Burton DR, Wilson IA. 2001. Crystal structure of a neutralizing human IgG against HIV-1: A template for vaccine design. Science 293, 1155-59

Vocadlo DJ, Davies GJ, Laine R, Withers SG. 2000. Catalysis by hen egg-white lysozyme proceeds via a covalent intermediate. Nature $412,835-838$

paid to selecting papers that discussed proteins across a range of contexts (e.g., ecological, medical, evolutionary, molecular, biochemical). Our overall expectation of students was to summarize the major findings of the article in their poster. Although the students were not expected to critique the article per se, they were expected to understand and analyze the article in order to select the information for presentation on the poster.

We were frank with the students about the difficulty of reading the articles, telling them they should plan to read their article several times and discuss it among their group members. They should not be surprised by the complexity and vocabulary of the articles; nor should they expect to understand everything for their presentation (for instance, they did not go into the methods in depth). We also told them that they might need to gain some background understanding of the protein's function from their text or from general review articles, which we helped students identify through on-line databases such as those for the Annual Reviews, General Science Abstracts, or MedLine. We made ourselves available for meetings with groups, typically providing background materials, answering questions about methods, defining vocabulary, or discussing the group's interpretations of their article.

\section{Poster Content and Session}

Because the articles differed in content, students were given a list of topics that they should try to include in the poster (see Table 3); not all topics were covered in each article. Enough background work was expected so that students could talk about the general function of their protein. The posters consisted of five to seven panels, including introduction and background sections and implications/interpretations panels. Additional panels included bulleted text that highlighted the protein's structural and functional features and a color diagram of the protein (when available and appropriate).

Each student stood in front of the poster for a share of the class period. During this time, students explained their poster to other members of the class and to the faculty as everyone circulated. This discussion with the faculty member was part of the evaluation of each student. Upper-class students and other biology and chemistry faculty also stopped by to talk with the presenters. A full 80-min class period was devoted to
Table 3. Poster Content ${ }^{a}$

Provide a background context for the protein's function in the cell. Try to answer the following questions:

- What features of protein are of particular interest?

- How does protein structure determine function?

- How does the article's content use the information we have covered in class (e.g., chemical nature of R-groups, types and importance of noncovalent bonds, role of conformational change in protein's function).

Provide a well-annotated diagram(s) of the protein.

What is the role of conformational change in the protein's function? How is the protein regulated?

${ }^{a}$ Because the articles differed in content, students were given a list of topics that they should try to include in the poster; not all topics were covered in each article.

the poster session; although this was sufficient time, a longer class period (e.g., a portion of a laboratory period) would allow greater time for faculty to discuss the poster with each student.

\section{Evaluation of Student Performance on the Assignment}

Students were given grades for their work based on three components: (1) the knowledge they displayed in the discussion with the faculty member; (2) the evaluations they received from their partners; and (3) the scientific content of the poster (evaluated at a later time than the actual poster session itself). A one-page questionnaire was given to students to evaluate their partner's contributions. This questionnaire attempted to determine how the work within the group was shared. When answers indicated that the workload was unequal, the faculty met with the group to discuss appropriate individual grades. Of the 77 students, faculty met with and adjusted only 2 student grades.

During the poster session, the faculty member discussed the poster content with each student author; this interview lasted 5-7 min. Because of the time constraints of a class period, sometimes an interview about a poster happened with the group rather than with individuals. When this occurred, the faculty member was directive about which students should answer a question since the goal was to be sure that all members of the group understood the poster content. Each year we performed one or two follow-up interviews outside of the class period for those students that had substantial difficulty explaining the poster content. This allowed us to be sure that the student's performance was not due primarily to nervousness.

\section{STUDENT PERCEPTIONS OF THE ASSIGNMENT'S SUCCESS IN MEETING THE STATED GOALS}

Students were asked to complete a two-page questionnaire after completion of the project. General information about the students and their previous experiences were collected (see Tables 1, 4, and 5). In addition, students were asked to circle a number ( 1 to 5 ) according to the extent to which they agreed with each of 17 statements ( 5 was high agreement). Table 4 
Table 4. Statements and average score for student responses in 2001 and $2002^{a}$

\begin{tabular}{|c|c|c|}
\hline & 2001 & 2002 \\
\hline \multicolumn{3}{|l|}{ Relating literature to course content } \\
\hline $\begin{array}{l}\text { This assignment helped me to visualize the various topics discussed in lecture about protein } \\
\text { structure and function. }\end{array}$ & $3.99 \pm 0.87$ & $3.74 \pm 0.85$ \\
\hline This article built on concepts we have covered in class. & $3.64 \pm 1.01$ & $3.66 \pm 1.09$ \\
\hline This assignment helped me to put what we were learning in class into a larger context. & $3.74 \pm 1.12$ & $3.63 \pm 1.04$ \\
\hline $\begin{array}{l}\text { This assignment helped me see that protein structure/function can be important to various levels } \\
\text { of biology. }\end{array}$ & $4.26 \pm 0.83$ & $4.06 \pm 0.87$ \\
\hline This assignment helped me understand more about how protein structures are determined.* & $3.80 \pm 0.96$ & $3.24 \pm 1.06$ \\
\hline \multicolumn{3}{|l|}{ Developing skills in reading literature } \\
\hline The assignment helped me learn to read research articles in depth.* & $4.21 \pm 0.81$ & $3.76 \pm 1.13$ \\
\hline The assignment built my confidence in reading difficult material.* & $4.31 \pm 0.75$ & $3.66 \pm 1.16$ \\
\hline The assignment helped me learn to focus my reading on the relevant material in an article. & $4.07 \pm 0.96$ & $3.83 \pm 1.12$ \\
\hline This assignment helped me learn to pick out the most important information in a complex article. & $4.05 \pm 0.85$ & $3.91 \pm 0.88$ \\
\hline \multicolumn{3}{|l|}{ Developing communication skills } \\
\hline This assignment helped develop my written skills in science. & $3.10 \pm 1.03$ & $2.94 \pm 0.97$ \\
\hline This assignment helped develop my oral skills in science. & $4.12 \pm 0.80$ & $3.74 \pm 0.96$ \\
\hline \multicolumn{3}{|l|}{ Student attitudes } \\
\hline This assignment created anxiety. & $3.08 \pm 1.21$ & $3.37 \pm 1.21$ \\
\hline This assignment was frustrating. & $2.57 \pm 1.23$ & $2.97 \pm 1.36$ \\
\hline The assignment was fun and exciting. & $3.70 \pm 1.03$ & $3.60 \pm 0.85$ \\
\hline The assignment was too hard for the level of the course. & $1.76 \pm 0.94$ & $1.63 \pm 0.84$ \\
\hline The assignment will help me in the future. & $4.01 \pm 0.72$ & $3.90 \pm 0.89$ \\
\hline I am very confident in my ability to read an article in the cellular/molecular area. & $3.49 \pm 0.85$ & $3.34 \pm 0.86$ \\
\hline
\end{tabular}

${ }^{a}$ Students replied to the following statements by circling a number from 1 to 5 , with 1 being low agreement and 5 being high agreement. Average responses, with the standard deviation, are reported independently for 2001 and 2002.

*Significant difference in student response $(p<.05)$ between 2001 and 2002.

provides a summary of the average score of the responses to these 17 statements, broken down by the year in which the assignment was given. Data were also collected on "total time" and "time with partners" spent for the assignment (Table 6). Several open-ended questions, including "What was the worst/best part of the assignment?" were included and responses to these are discussed.

The statements on which students were asked to rate their agreement (Table 4) can be divided into several categories roughly corresponding to the course goals: relating their paper to course content and a larger context, developing skills in reading research articles, and developing communication skills. Attitudes toward the assignment were also assessed.

Table 5. Student experience reading research articles ${ }^{a}$

\begin{tabular}{lrcr}
\hline & Previous & This assignment & $p$-value \\
\hline Abstract & $4.65 \pm 0.71$ & $4.64 \pm 0.86$ & .915 \\
Introduction* $_{\text {Materials and Methods* }}^{*}$ & $4.56 \pm 0.67$ & $4.88 \pm 0.34$ & $<.001$ \\
Results* & $4.90 \pm 0.97$ & $3.29 \pm 1.44$ & .041 \\
Conclusion/Discussion & $4.74 \pm 0.85$ & $4.46 \pm 0.87$ & $<.001$ \\
& & $4.85 \pm 0.39$ & .073 \\
\hline
\end{tabular}

${ }^{a}$ Students were asked to indicate on a scale of 1 to 5 the extent to which they had used portions of a research article in previous assignments and for this assignment. The average responses and standard deviations are reported. Data from the 2 years in which the assignment was given were combined. $p$-values for post hoc paired $t$-tests are provided.

* Significant difference between previous reading and reading for this assignment.

\section{Putting Material in the Article into a Biochemical and Larger Biological Context}

We hoped that this assignment would provide concrete examples to illustrate: the dependence of function on structure; the importance of protein structure to a variety of levels of function, and the importance of chemical principles in understanding proteins. These topics were covered in the first few weeks of the course, with the assignment occurring at about midterm. As such, we expected students to review, integrate, and apply principles of protein structure and function in a new situation.

Responses to questions in this area averaged above $3.24 \pm$ 1.06 and the responses were not significantly different between the 2 years in which the assignment was used. The average scores for the question "How much did your article build on concepts we have covered in class?" were 3.64 and

Table 6. Student time spent on the assignment ${ }^{a}$

\begin{tabular}{cccccc}
\hline & \multicolumn{2}{c}{2001} & & \multicolumn{2}{c}{2002} \\
\cline { 2 - 3 } \cline { 5 - 6 } & $\begin{array}{c}\text { Total time } \\
\text { spent }\end{array}$ & $\begin{array}{c}\text { Time spent } \\
\text { with partners }\end{array}$ & $\begin{array}{c}\text { Total time } \\
\text { spent }\end{array}$ & $\begin{array}{c}\text { Time spent } \\
\text { with partners }\end{array}$ \\
\hline$>6 \mathrm{~h}$ & $65 \%$ & $40 \%$ & & $50 \%$ & $24 \%$ \\
$5-6 \mathrm{~h}$ & $33 \%$ & $35 \%$ & & $44 \%$ & $41 \%$ \\
$3-4 \mathrm{~h}$ & $2 \%$ & $23 \%$ & & $6 \%$ & $32 \%$ \\
$1-2 \mathrm{~h}$ & $0 \%$ & $3 \%$ & & $0 \%$ & $3 \%$ \\
\hline
\end{tabular}

${ }^{a}$ Percentages of students responding with the total hours spent on the assignment and the hours spent with partner(s) are given for 2001 and 2002. 
3.66 in 2001 and 2002, respectively. In an open-ended question asking which concepts were relevant in understanding the article, one-third (26) of the students indicated that their article built on general concepts of protein structure (e.g., secondary structures, weak bonding patterns, amino acid structure). Also commonly mentioned by students in answer to this open-ended question were the interdependence of structure and function (14 responses), the interaction of a protein with other components (proteins, ligands, substrates, allosteric regulators) (11 responses), and the role of conformational change in protein function (8 responses). Given these responses, we believe that the assignment required students to review and apply basic concepts in protein structure and function.

Concepts beyond basics of protein structure (e.g., enzyme mechanisms, signal transduction, membrane structure) were mentioned 28 times in response to the open-ended question asking which cellular concepts were relevant to their article. Given the general resistance of our students to learning bioenergetics, it was gratifying that seven persons mentioned concepts relating to thermodynamics (e.g., free energy, coupling of reactions). Concepts covered in our first-year course (e.g., transcription, DNA structure, gene regulation, cell sorting) were mentioned 12 times. Average scores of 3.99 and 3.74 were obtained in 2001 and 2002, respectively, when students were asked to respond to the statement, "The assignment helped to visualize the various topics covered up to that point in the cell physiology course." Clearly, students believe that they were using and expanding previously acquired knowledge in understanding their article.

A factor used by faculty for selecting the research articles was that they illustrated protein functions at an organization level more complex than cellular physiology. For instance, in 2001, the article by Liou et al. was included since it discussed the role of protein structure in the antifreeze properties of insect hemolymph (see Table 2). Our evaluation shows that students did find this assignment helpful in seeing the importance of proteins to other biological areas. When asked whether the assignment helped them put class content into a larger context, the scores from the 2001 and 2002 classes were 3.74 and 3.63, respectively. Similarly, an average score of 4.26 and of 4.06 was obtained in 2001 and 2002, respectively, when students were asked if the assignment helped them see that protein structure/function can be important to various levels of biology. We also observed student groups selecting their article based, in part, upon their interests in these larger ecological, medical, or physiological connections. In the open-ended questions about the best and worst parts of the assignment, nine students mentioned seeing details of protein structure and function in a larger context (e.g., medical applications, function of human body) as one of the best features of the assignment. Again, it appears that the assignment was successful in helping students appreciate the interdependence of various levels of biology.

\section{Development of Skills in Reading Research Articles}

A major goal of this assignment was to improve students' ability to read and understand research articles. Students were asked to indicate (on a scale of 1 to 5 , with 5 being the highest) how carefully they had read various sections of research articles in the past. Another set of questions asked students to indicate how carefully they had read the various portions of their article for this assignment. Data from the 2 years were pooled (Table 5). A repeated-measures ANOVA was used to compare how carefully students read a section before the assignment and how carefully they read the section for this assignment. There were significant differences in students' reading of the introduction $(p<.001)$, materials and methods $(p<.05)$, and results $(p<.001)$ sections for this assignment compared to previous ones (Table 5). There was a nonsignificant trend for reading the discussion/conclusion section more carefully for this assignment (Table 5) than for previous assignments. No significant difference was observed between the reading of the abstract previously and that for this assignment.

This pattern, with students reading the introduction, materials and methods, and results sections more carefully than previously, while not reading the abstract and discussion/conclusion sections more carefully for this assignment than previous ones, is gratifying. It is in fact consistent with our department's attempt to expect progressively greater engagement with research articles as students move through their undergraduate careers. Assignments in the first year are structured so that they can be completed with careful reading of the abstract and discussion sections. These data for the cell physiology course provide evidence that the assignment described here was successful in increasing student engagement in research articles, requiring more careful reading of various sections of article.

These data were collected from the questionnaire given to students at the end of the project. Exactly how this timing influenced students' answer is unclear. Since students could reflect on their previous experiences in light of their encounter with the research article for this assignment, they might have been more accurate in their reporting of prior use of an article's components. However, collecting data about prior experience after completion of the assignment might have made it difficult for students to delineate clearly their previous experiences from the current one.

Students also were asked whether the assignment helped them: (1) learn to read research articles in depth, (2) focus on reading relevant material in an article, and (3) pick out the most important information in a complex article. Student responses in both 2001 and 2002 for these questions were all above 3.60 (Table 4 ).

In open-ended questions in which students were asked about the best and worst parts of the assignment, 16 persons indicated that the complexity/density/difficulty of their article was the worst part. However, 18 persons indicated that "conquering" their article or coming to understand difficult material was one of the best parts of the assignment. Often the same student responded that both the best and the worst part of the assignment was the difficulty of the article. During the conversations with students at the poster sessions, students were knowledgeable about both the general information and the details of their articles. Even the weakest students were able to discuss the general structural and functional features of the protein.

Furthermore, the average scores for the statement "The assignment was too hard for the level of the course" were 1.76 and 1.63 in 2001 and 2002, respectively. These low scores, along with the reports of the enjoyment at working through difficult material and the students' success at discussing 
their articles, indicate that students generally rose to the challenge.

Overall, students perceive that the assignment did require them to read articles more closely and carefully than they had in the past and to be selective in that reading. It helped them gain experience in focusing their reading and in picking out the most relevant information for their purpose. Although students found the articles difficult and complex, they were successful in extracting information from them.

\section{Developing Skills in Communication}

Providing opportunities for students to further develop skills in communicating science in written and oral form is another way in which undergraduate courses can model the activities of professional scientists. Earlham's introductory biology curriculum has numerous opportunities for building writing skills. Fewer opportunities are available at this level for practicing oral skills. We saw the poster format as a way for students to "talk science" in a relatively nonthreatening environment. Importantly, we also saw the poster format as a way that faculty could manage grading nearly 40 students in part on their ability to communicate orally.

Students in 2001 thought that the assignment was helpful in developing written (average score, 3.10) skills. Not surprisingly, the average response for development of oral communication skills was a point higher (average score, 4.12). Similar scores were given by students in 2002: 2.94 and 3.74 for development of written and oral skills, respectively. When asked specifically how their skills improved, students indicated that the assignment provided opportunities for selecting the most critical aspects of the research to include, developing their vocabulary in the field, and building confidence in their speaking/explaining abilities. A number of students indicated that the oral component pushed them to understand the article more fully so that they could explain it to peers and faculty.

Not only did students feel that they developed their communication skills, but many also enjoyed the experience; 22 of the students indicated in the open-ended questions that the best part of the project was the presentation. Several students wrote specifically about how explaining information to their peers was a highlight of the project. Two students did indicate that the presentation was the worst part of the assignment; an additional three persons indicated that their nervousness/anxiety about presenting was the worst part.

We were pleased with the degree to which the poster format provided students a mechanism to hone their communication skills, particularly their ability to "talk science."

\section{Developing Skills in Group Work}

There were several reasons we chose to have the students work in groups of two or three, not least of which was being able to manage the grading. We also were hopeful that students would use each other to decipher their articlepromoting peer learning and modeling the activities of scientists working through a "problem." We promoted peer interaction for this assignment in our instructions and required students, whenever possible, to bring questions to faculty in their groups. We also made clear that students were responsible for all aspects of their poster content, not just whatever piece on which an individual might have focused.
We asked students about the amount of time they spent on this project (Table 6). Ninety-eight percent of the students in 2001 indicated that they spent more than 5 h. In 2002, 94\% spent more than $5 \mathrm{~h}$ on the assignment. There was not a statistically significant difference $(t$-test; $p>.005)$ between the amount of time students report spending on the assignment in 2001 and that in 2002.

Of this time, students spent a considerable part of it with each other deciphering their articles (Table 6). In 2001, 75\% said that they spent more than $5 \mathrm{~h}$ working with their partner(s) on the assignment. In 2002, 64\% spent more than $5 \mathrm{~h}$ with their partners. When asked "How much did talking with your partner(s) help you understand the content of the article?" the average score was 4.43 in 2001 and 4.07 in 2002. Not only were the students spending the majority of time together reading the articles, but they clearly relied on each other to analyze the contents of the article. In the open-ended questions, eight persons indicated that the best part of the assignment was talking with their partner(s) about the paper and onethird of the classes indicated that discussing their poster with their peers was the best part.

Group work does not always go smoothly. Five persons mentioned difficulties with group dynamics as one of the worst parts of the assignment. Difficulty finding meeting times was mentioned another four times. Faculty also intervened in two instances by calling a meeting with all group members when groups were obviously dysfunctional. In one instance, the meeting with faculty was sufficient to rectify the lack of participation of one group member in the time remaining on the project. In the second instance, which fortunately was a group of three, the nonparticipatory person agreed to take a no-pass for the assignment. This individual later dropped the course.

Although we did not specifically set out to assess the development of specific collaborative skills, the information we do have indicates that students were working together for the bulk of the time they spent on the assignment. In addition, the vast majority enjoyed working with their partner(s) to understand the paper.

\section{A Bonus: Building Confidence}

One of the satisfying features of this assignment was the relatively large number of students (19) that indicated that the best part of the assignment was the sense of confidence or accomplishment at having figured out the article. Students in 2001 reported an average score of 4.31 when asked whether the assignment built confidence in reading difficult material. The average score in 2002 was 3.66. Average scores of 3.49 and 3.34 (2001 and 2002, respectively) were given in response to the statement "I am very confident in my ability to read an article in the cellular/molecular area of biology." These results were especially satisfying given that $60 \%$ of the students indicated that they were somewhat or not confident at the outset of the assignment in their ability to read articles in this area (Table 1).

\section{STUDENT ATTITUDE TOWARD THE ASSIGNMENT}

Students generally liked the project. They gave a relatively high average score in both years when asked whether it was 
fun and exciting (Table 4). That the assignment created some anxiety was evident in the average score for the statements "This assignment created anxiety" and "This assignment was frustrating" (see Table 4) and in the fact that nine persons mentioned anxiety/frustration as one of the worst parts of the assignment. Ninety-six percent of the total students answered "yes" when asked whether the assignment should be included in the future.

\section{FACULTY PERCEPTIONS OF STUDENT PERFORMANCE ON THE ASSIGNMENT}

Quantitative assessment of the assignment was limited to student perceptions of their learning based on their responses in the two-page questionnaire. Comparative evaluations of student learning with this assignment versus learning in previous years was not possible since introduction of this assignment accompanied a major curricular reorganization, including a change of academic calendar. Comparison of student perceptions with actual grades received on the assignment is confounded by the fact that the course was taught by different faculty in the separate years.

Most of the data indicate what students believe/report about their attitudes and learning rather than provide evidence for what students actually learn. However, student responses to the open-ended questions do provide a preliminary assessment of actual student learning. That 51 of $77 \mathrm{stu}-$ dents named specific concepts relating to protein structure/ function (e.g., weak bonding, interaction of proteins with other cellular components, conformational change, free energy change, feedback inhibition) indicates their ability to recognize that their articles used concepts they had learned in class. It also shows that students have applied those concepts in a new situation, not just reiterated material given in class. Likewise, answers to the open-ended questions provide evidence that students came to understand a protein in a larger cellular or physiological context; many (28) students identified connections with other concepts (e.g., immunology, transcription regulation, cell-cell communication, membrane function, membrane potential, preeclampsia).

Faculty interaction with and observation of students as they progressed through the assignment also indicated that they improved their understanding of protein structure and function. At the outset, student confusion about the content of their articles was high as indicated by the basic level of questions asked of faculty. At later times, students were asking more sophisticated questions. Furthermore, the ability of students to converse intelligently about the content and implications of their article in the interview with faculty indicated that students had a level of understanding about their specific protein beyond merely the concepts that had been taught in class. When one student talked at the poster session about the specific changes in intramolecular bonding patterns among $\alpha$-helices in response to ligand binding, and another spoke of the relative positions of a catalytic residue pre- and postbinding of a substrate, the increase in understanding of protein structure and function as a consequence of careful reading of the assigned article was obvious. Quantitative measurement of actual student learning as a result of this assignment is under way. A tool that uses performance on exam questions prior to exposure to the material in class, following lectures on protein structure and function and then following this assignment, will be developed.

A goal of the assignment was to improve students' ability to work with scientific research articles. As such, this assignment is one in a series within the biology major curriculum that relies on the scientific literature. Although no formal evaluation has been performed, my own observations of students in upper-level classes that have completed the assignment in the cell physiology course indicate that they are more sophisticated and careful readers than those students from years before the assignment was introduced.

\section{TRANSFERABILITY TO OTHER INSTITUTIONS}

Although the assignment was used in 2 different years by different faculty, the instructions provided to students and the overall structure of the assignment were the same in both years. The greatest difference in the mechanics of this assignment between 2001 and 2002 was the length of time given to students to complete the assignment. A shorter time period ( 2 weeks) was allotted in 2002 than in 2001 (4 weeks). Despite this difference, $t$-tests comparing the students' responses to the questions in Table 4 in 2001 versus 2002 showed a significant difference $(p<.05)$ in only three of the questions: "This assignment helped me understand more about how protein structures are determined;" "The assignment helped me learn to read research articles in depth;" and "The assignment built my confidence in reading difficult material." In each of these cases, the average responses to the questions in 2001 were higher than in 2002.

Another difference between the 2 years was the number of students (or their partner) that met with faculty to discuss the article: In 2001, 78\% of the students reported meeting with a faculty member; in 2002 , only $33 \%$ met with a faculty member. A one-tailed $t$-test was done to compare responses of students who met with faculty versus those who did not for the three questions on which there was a significant difference in responses between 2001 and 2002. There were significant differences ( $p<.05$ ) in the responses for all three questions, with the persons meeting with faculty reporting higher values in response to the three questions. Thus, it appears that student meetings with faculty enhance student confidence, understanding of method, and depth of reading with respect to this assignment.

Another factor that might have contributed to the significant differences in student responses could be the length of time allotted for the assignment; a greater period was given in 2001 versus 2002. However, the length of time given for the assignment does not appear to explain these differences completely; there was not a statistically significant difference ( $t$-test; $p>.05)$ in the amount of time students report spending on the assignment in 2001 versus 2002. Although there also was no significant difference in the scores of any other questions relating to student attitude about the assignment, the greater number of 2002 students (10) than 2001 students (2) indicated in an open-ended question that the worst part of the assignment was not having enough time.

The overwhelming similarity in student responses between 2001 and 2002, when different faculty were teaching the course, indicates a strong likelihood that the success of the assignment is somewhat independent of specific faculty. This suggests that the project could be adapted for use at other 
institutions and in other courses. An important factor to student engagement, enjoyment, and satisfaction with the project appears to be having sufficient time to work on it. Student confidence, understanding of methods, and reading in depth can be positively influenced by student-faculty meetings to discuss the articles.

\section{DISCUSSION AND GENERAL CONSIDERATIONS}

Project Kaleidoscope (PKAL, 2003) puts forth three attributes of a strong undergraduate science program. First, such programs are "experiential and steeped in investigation." In addition, they create environments where "learning is personally meaningful for students and faculty, makes connections to other fields of inquiry, is embedded in the context of its own history and rationale, and suggests practical applications related to the experience of students." Finally, a strong undergraduate science program is characterized by a learning community where faculty and students are partners in the educational process and where students collaborate with one another.

The assignment described here embodies these aspects of teaching and learning. Students participate in the classroom community in a sophisticated experiential way, constructing their own knowledge and taking responsibility for the learning process. The expectation is that each student becomes an expert in a topic area of his/her choice and will share that expertise with peers and faculty. Success relies on application and extension of knowledge previously gained. The process, because of the difficulty of reading the scientific articles, requires students to collaborate.

From a personal viewpoint, I have found this assignment to be one of the highlights of teaching the cell physiology course. Interacting with the students when they are the experts on a topic is rewarding and exciting. Many take great pride in their poster and in their knowledge of the protein. The format provides an opportunity to tailor my oral questions to the ability of the student, challenging the best while still being supportive of the less able students. In fact, I am often surprised by the depth of understanding of a student whose performance had been otherwise mediocre. This assignment is also a mechanism by which I can keep abreast of new findings in a wide variety of areas. In this sense, the assignment does promote a community of learners that even includes faculty.

At a time when faculty are looking for ways to enrich their curriculum to better model the activities of professional biologists and to enhance the learning community in undergraduate science, this assignment, in which students read and report on a single research article dealing with protein structure and function, may be useful in other curricula.

\section{ACKNOWLEDGMENTS}

Thanks are due to the students in the cell physiology course at Earlham College in 2001 and 2002 for filling out the assessment questionnaires. Many thanks go to Sara Penhale and Janet Russell for their comments on the manuscript and to Kathy Milar for her help with the statistical analysis. Nathan Trueblood and William Harvey were the other faculty members who taught cell physiology during this time; their encouragement and willingness to try something new made this assignment possible. The results from 2001 were presented at the 2001 FASEB meetings. Support for the revision of the assignment came in part from 2000-2004 Howard Hughes Medical Institute Grant 52002642 to Earlham College.

\section{REFERENCES}

Edwards, R., White, M., Gray, J., and Fischbacher, C. (2001). Use of a journal club and letter-writing exercise to teach critical appraisal to medical undergraduates. Med. Educ. 35, 691-694.

Herman, C. (1999). Reading the literature in the jargon-intensive field of molecular genetics. J. Coll. Sci. Teach. 28(4), 252-254.

Higher Education Data Sharing Consortium and Franklin and Marshall College. (2002). Weighted Baccalaureate Origins Study.

Janick-Buckner, D. (1997). Getting undergraduates to critically read and discuss primary literature. J. Coll. Sci. Teach. 27(1), 29-32.

Levine, E. (2001). Reading your way to scientific literacy. J. Coll. Sci. Teach. 31(2), 122-125.

Mulnix, A., and Penhale, S. (1997). Modeling the activities of scientists: A literature review and poster presentation. Am. Biol. Teach. 59(8), 482-487.

National Research Council. (2003). Biology 2010: Transforming Undergraduate Education for Future Research Biologists, Washington, DC: National Academies Press.

NSF Division of Undergraduate Education. (1996). Shaping the future: New expectations for undergraduate education in science, mathematics, engineering and technology. A report on the review of undergraduate education from the Committee for the Review to the National Science Foundation Directorate for Education and Human Resources. http://www.ehr.nsf.gov/ehr/due/ documents/review/96139/start.htm (accessed June 3, 2003).

PKAL. (2003). What works: Programs. http://www.pkal.org/ template2.cfm?c_id=258 (accessed June 6, 2003).

Rothman, F.G., and Narum, J.L. (1999). Then, now, and in the next decade: A commentary on strengthening undergraduate science, mathematics, engineering and technology education. Project Kaleidoscope.

Stephenson, W.K. (1993). A departmental approach to bibliographic instruction. In: Bibliographic Instruction in Practice, eds. Hardesty, L., Hastreider, J., and Henderson, D., Ann Arbor MI: Pierian Press. 